\title{
Antibacterial studies of dihydropyrimidinones and pyrimidinethiones
}

\begin{abstract}
Some new dihydro pyrimidinone and pyrimidinethione compounds have been synthesized and their antibacterial activities have been studied in dimethyl formamide and dimethyl sulphoxide against some Gram positive and Gram negative bacteria. For this, Agar well diffusion method is used. It is observed that inhibition depends on solvent, bacterial strain, nature and position of substitution in a compound. When the same substitution is attached to different moieties its effect on bacterial strains changes in different solvents.
\end{abstract}

Keywords: dihydro pyrimidinone, pyrimidinethione, dimethyl formamide

\author{
Volume 5 Issue 6 - 2017
}

\author{
Shipra Baluja,' Ravi Gajera,' Sumitra Chanda ${ }^{2}$ \\ 'Department of Chemistry, Saurashtra University, India \\ ${ }^{2}$ Department of Biosciences, Saurashtra University, India
}

\section{Correspondence: Shipra Baluja, Department of Chemistry, Saurashtra University, Rajkot 360 005, Gujarat, India,} Email Shipra_baluja@rediffmail.com

Received: November 20, 2017 | Published: December 08, 2017

\section{Introduction}

The extensive use of antibiotics resulted in the multiple drug resistant pathogens. This highlights the need for the development of new classes of antimicrobial agents and alteration of known drugs in such a way that would allow them to retain their resistance to the pathogen. So, chemists and pharmacists are always in search of new drugs molecules.

Heterocyclic compounds containing nitrogen are promising structure moiety for drug design. Dihydropyrimidines are one of the important heterocyclic compounds, which are of interest due to its efficiency towards various pharmacological uses. These are large group of structurally diverse compounds which are known to possess some characteristic properties like manifestations of novel structures, thermal stability, relevant biological properties, high synthesis flexibility and medicinal utility. ${ }^{1-12}$ Further, some of dihydropyrimidines are reported to overcome multidrug resistance efficiently. ${ }^{13}$

Thus, in the present paper, some new dihydropyrimidinone and pyrimidinethione compounds (shown in Figure 1) have been synthesized and their antibacterial activities have been studied in dimethyl formamide and dimethyl sulphoxide against some Gram positive and Gram negative bacteria.<smiles>[R]c1ccc(NC(=O)C2=C(C)NC(=O)NC2c2ccc(OC)c(OC)c2)cc1</smiles><smiles>[R]c1ccc(NC(=O)C2=C(C)NC(=S)NC2c2ccc(OC)c(OC)c2)cc1</smiles>

SOR SSR
Figure I General structure of dihydropyrimidinone (SOR) and pyrimidinethione (SSR) compounds.

\section{Materials and methods}

\section{Synthesis}

Synthesis of dihydropyrimidinone derivatives: (i) Synthesis of 3 , 4-dimethoxybenzaldehyde: An aqueous solution was vanilline was refluxed for half an hour with stirring at $100^{\circ} \mathrm{C}$. To this solution, few drops of $\mathrm{NaOH}$ and dimethyl sulphate were added slowly and the reaction mixture was again refluxed with stirring for about 4hours. In this reaction mixture, diethyl ether was added and the solvent was evaporated to get the crude product 3,4-dimethoxybenzaldehyde. (ii) Synthesis of 3-oxa-N-phenylbutanamide: To an equimolar mixture of substituted aniline and ethyl aceto acetate in toluene, few drops of $\mathrm{NaOH}$ solution was added and the solution was refluxed for 12 hours. The excess of toluene was distilled out and the reaction mixture was taken in hexane and stirred. The product was isolated and was dissolved in $\mathrm{NaOH}$ solution. This solution was then neutralized with dilute hydrochloric acid and product was separated. (iii) Synthesis of 4-(3,4-dimethoxyphenyl)-6-methyl-2-oxa-N-phenyl-1, 2, 3, 4-tetra hydropyrimidine-5-carboxamide: A methanolic solution of 3, 4-dimethoxy aldehyde, substituted diketones and urea was refluxed for 12 hours using conc. $\mathrm{HCl}$ as catalyst. After the completion of reaction, product was isolated and recrystallized from ethanol. Similarly other compounds were synthesized.

Synthesis of pyrimidinethione derivatives: (i) Synthesis of 3, 4-dimethoxybenzaldehyde: As above. (ii) Synthesis of 3-oxa-N-phenylbutanamide: As above. (iii) Synthesis of 4-(3,4-dimethoxyphenyl)-6-methyl-N-phenyl-2-thioxo-1,2,3,4tetrahydropyrimidine -5-carboxamide: A methanolic solution of 3,4-dimethoxy aldehyde, 3-oxo-N-phenylbutanamide and thiourea was refluxed for 12 hours using conc. $\mathrm{HCl}$ as catalyst. After the completion of reaction, product was isolated and recrystallized from ethanol. Similarly other compounds were synthesized.

The physical parameters along with substitution groups of synthesized compounds are listed in Table 1.

\section{Antimicrobial activity}

The antibacterial activities of all the synthesized compounds were 
studied in dimethyl sulphoxide (DMSO) and dimethylformamide (DMF) using Agar well diffusion method. The solvent DMSO and DMF were also purified before use by standard method. ${ }^{14}$

Table I Physical data and substitution groups of synthesized compounds

\begin{tabular}{|c|c|c|c|c|c|c|}
\hline Compound code & $\mathbf{R}$ & M.Wt. (g) & M.F. & RfValue & M.P. ${ }^{\circ} \mathrm{C}$ & Yield \% \\
\hline \multicolumn{7}{|l|}{ RVG series } \\
\hline SOR-I & $4-\mathrm{OCH}_{3}$ & 397 & $\mathrm{C}_{21} \mathrm{H}_{23} \mathrm{~N}_{3} \mathrm{O}_{5}$ & 0.61 & 168 & 53 \\
\hline SOR-2 & $4-\mathrm{CH}_{3}$ & 381 & $\mathrm{C}_{21} \mathrm{H}_{23} \mathrm{~N}_{3} \mathrm{O}_{4}$ & 0.54 & 152 & 57 \\
\hline SOR-3 & $4-\mathrm{Cl}$ & 401 & $\mathrm{C}_{20} \mathrm{H}_{20} \mathrm{~N}_{3} \mathrm{O}_{4} \mathrm{Cl}$ & 0.49 & 179 & 46 \\
\hline SOR-4 & $2-\mathrm{CH}_{3}$ & 381 & $\mathrm{C}_{21} \mathrm{H}_{23} \mathrm{~N}_{3} \mathrm{O}_{4}$ & 0.47 & 182 & 62 \\
\hline SOR-5 & $3-\mathrm{OCH}_{3}$ & 397 & $\mathrm{C}_{21} \mathrm{H}_{23} \mathrm{~N}_{3} \mathrm{O}_{5}$ & 0.54 & 164 & 45 \\
\hline SOR-6 & $4-\mathrm{F}$ & 385 & $\mathrm{C}_{20} \mathrm{H}_{20} \mathrm{~N}_{3} \mathrm{O}_{4} \mathrm{~F}$ & $0.7 I$ & 160 & 59 \\
\hline SOR-7 & 2,5-di Cl & 436 & $\mathrm{C}_{21} \mathrm{H}_{19} \mathrm{~N}_{3} \mathrm{O}_{4} \mathrm{Cl}_{2}$ & 0.37 & $17 \mid$ & 72 \\
\hline SOR-8 & $3-\mathrm{Cl}$ & 401 & $\mathrm{C}_{21} \mathrm{H}_{20} \mathrm{~N}_{3} \mathrm{O}_{4} \mathrm{Cl}$ & 0.62 & 198 & 62 \\
\hline SOR-9 & 3,4- di Cl & 436 & $\mathrm{C}_{21} \mathrm{H}_{19} \mathrm{~N}_{3} \mathrm{O}_{4} \mathrm{Cl}_{2}$ & 0.66 & 169 & 77 \\
\hline SOR-IO & $3-\mathrm{Cl}, 4-\mathrm{F}$ & 419 & $\mathrm{C}_{21} \mathrm{H}_{19} \mathrm{~N}_{3} \mathrm{O}_{4} \mathrm{CIF}$ & 0.52 & 145 & 78 \\
\hline \multicolumn{7}{|l|}{ SRG series } \\
\hline SSR-I & $4-\mathrm{OCH}_{3}$ & 413 & $\mathrm{C}_{21} \mathrm{H}_{23} \mathrm{~N}_{3} \mathrm{O}_{4} \mathrm{~S}$ & 0.49 & 211 & 63 \\
\hline SSR-2 & $4-\mathrm{CH}_{3}$ & 397 & $\mathrm{C}_{21} \mathrm{H}_{23} \mathrm{~N}_{3} \mathrm{O}_{3} \mathrm{~S}$ & 0.53 & 194 & 56 \\
\hline SSR-3 & $4-\mathrm{Cl}$ & 417 & $\mathrm{C}_{20} \mathrm{H}_{20} \mathrm{~N}_{3} \mathrm{O}_{3} \mathrm{ClS}$ & 0.46 & 224 & 66 \\
\hline SSR-4 & 2- $\mathrm{CH}_{3}$ & 397 & $\mathrm{C}_{21} \mathrm{H}_{23} \mathrm{~N}_{3} \mathrm{O}_{3} \mathrm{~S}$ & 0.49 & 232 & 61 \\
\hline SSR-5 & $3-\mathrm{OCH}_{3}$ & 413 & $\mathrm{C}_{21} \mathrm{H}_{23} \mathrm{~N}_{3} \mathrm{O}_{4} \mathrm{~S}$ & 0.62 & 215 & 75 \\
\hline SSR-6 & $4-\mathrm{F}$ & 401 & $\mathrm{C}_{20} \mathrm{H}_{20} \mathrm{~N}_{3} \mathrm{O}_{3} \mathrm{FS}$ & 0.7 & 248 & 59 \\
\hline SSR-7 & 2,5-di Cl & 452 & $\mathrm{C}_{21} \mathrm{H}_{19} \mathrm{~N}_{3} \mathrm{O}_{3} \mathrm{Cl}_{2} \mathrm{~S}$ & 0.59 & 251 & 70 \\
\hline SSR-8 & $3-\mathrm{Cl}$ & 417 & $\mathrm{C}_{21} \mathrm{H}_{20} \mathrm{~N}_{3} \mathrm{O}_{3} \mathrm{ClS}$ & 0.82 & 219 & 65 \\
\hline SSR-9 & 3,4- di Cl & 452 & $\mathrm{C}_{21} \mathrm{H}_{19} \mathrm{~N}_{3} \mathrm{O}_{3} \mathrm{Cl}_{2} \mathrm{~S}$ & 0.63 & 263 & 67 \\
\hline SSR-10 & $3-\mathrm{Cl}, 4-\mathrm{F}$ & 435 & $\mathrm{C}_{21} \mathrm{H}_{19} \mathrm{~N}_{3} \mathrm{O}_{3} \mathrm{CIFS}$ & 0.7 & 201 & 72 \\
\hline
\end{tabular}

Test microorganisms: The synthesized compounds were tested for its antibacterial activity against Gram positive bacteria viz. Staphylococcus aureus ATCC 25923, Bacillus cereus ATCC 11778, Bacillus megaterium ATCC 9885 and Gram negative bacteria viz. Salmonella typhimurium ATCC 23564, Proteus mirabilis NCIM 2241 and Klebsiella pneumoniae NCIM 2719. Microorganisms were obtained from National Chemical Laboratory (NCL), Pune, India. These microorganisms were maintained at $4^{\circ} \mathrm{C}$ using nutrient agar slants.

Agar well diffusion method: The antimicrobial study of synthesized compounds were done by agar well diffusion method. The bacterial strains were activated by inoculating in $25 \mathrm{ml}$ of N-broth. This mixture was incubated for $24 \mathrm{~h}$ in an incubator at $37^{\circ} \mathrm{C} .0 .2 \mathrm{ml}$ of the activated strain was incubated in Mueller Hinton Agar. The nutrient medium Mueller Hinton agar was kept at $45^{\circ} \mathrm{C}$ and was then poured in Petri dishes. These dishes are then left without disturbance so that the medium should be solidified. Using a sterile cork borer, $0.85 \mathrm{~cm}$ well was made in the Petri dishes and in each well, $0.1 \mathrm{ml}$ of test solution was filled. These dishes were then incubated for $24 \mathrm{~h}$ at $37^{\circ} \mathrm{C}$. For each bacterial strain, three experiments were done for each compound and mean value was used as zone of inhibition for each sample. The
Preparation of the test compound: The synthesized compounds were dissolved in DMF and DMSO at a concentration of $1 \mathrm{mg} / \mu 1$. inhibition was also measured for pure DMSO or DMF for each strain, which was considered as control. The zone of inhibition for each compound in each strain is given after subtraction of zone of control.

\section{Results and discussion}

For all the synthesized compounds, physical parameters are given in Table 1 along with substitution group.

\section{Antibacterial activity}

1, 4-dihydropyrimidinones: Figure 2 shows the zone of inhibition against the Gram positive bacteria in DMSO. It is observed in DMSO that against $S$. aureus, SOR-7 exhibited maximum inhibition and SOR-8 showed minimum inhibition. SOR-1, SOR-2, SOR-4, SOR6, SOR-9 and SOR-10 showed no inhibition at al. For B. cereus, again, SOR-7 showed maximum inhibition whereas SOR-9 and SOR-10 exhibited minimum inhibition. SOR-4 and SOR-6 showed no inhibition at all. Against B. megaterium, only SOR-7 exhibited maximum inhibition whereas SOR-10 showed minimum inhibition. SOR-4 had no inhibition. Thus, in DMSO, SOR-7 is most effective compound in the studied bacteria. 


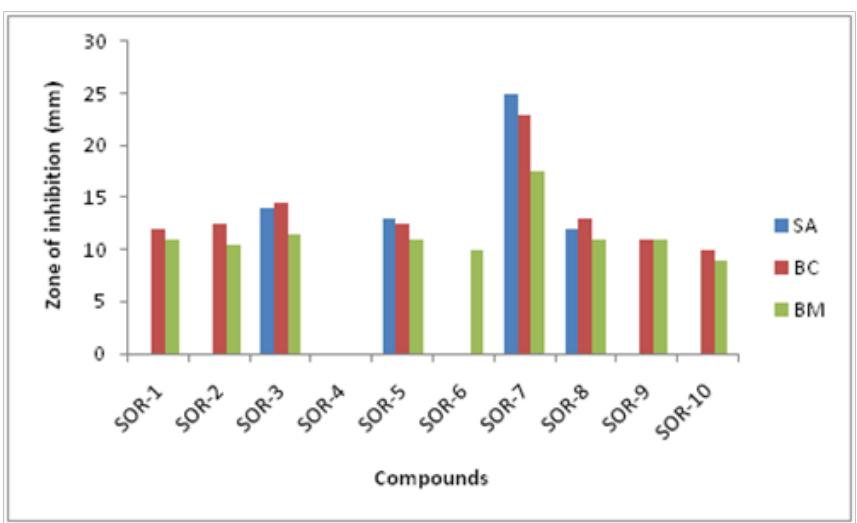

Figure 2 Zone of inhibition of SOR compounds against Gram positive bacteria in DMSO.

In DMF, zone of inhibition against Gram positive bacteria is given in Figure 3. It is observed that again SOR-7 showed maximum inhibition for all the three bacterial strains. For $S$. aureus and $B$. cereus, SOR-4 and SOR-6 shows no inhibition at all whereas for $B$. megaterium, all the compounds show inhibition.

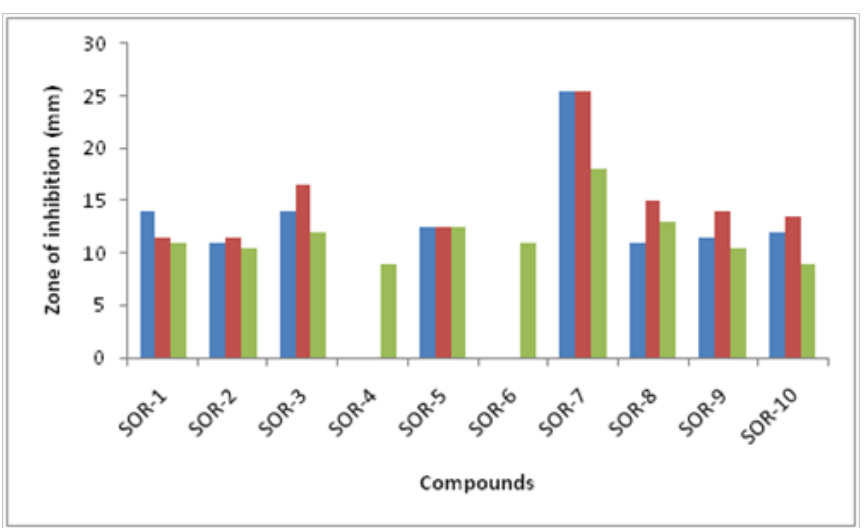

Figure 3 Zone of inhibition of SOR compounds against Gram positive bacteria in DMF.

Thus, for both DMSO and DMF, B. megaterium is the most susceptible bacteria and SOR-4 and SOR-6 show no inhibition against $S$. aureus and B. cereus. The inhibition depends on solvent, strain and structure of the compound. SOR-4 and SOR-6 contain 2-methyl and 4-fluoro group respectively. Thus, these substitutions are not effective against $S$. aureus and $B$. cereus. On the other hand, the presence of 2,5-dichloro groups (as in SOR-7) increases the inhibition in the studied solvents for these bacteria. Other substitutions have an intermediate effect.

Figure 4 shows the zone of inhibition against Gram negative bacteria in DMSO. It is observed again the inhibition is maximum for SOR-7 against all the three bacterial strains. For S. typhimurium, only SOR-5 and SOR-7 showed inhibition and other compounds had no inhibition at all. For K. pneumonia, SOR-1, SOR-4, SOR-5 and SOR9 did not effect. Against P. mirabilis, SOR-4 and SOR-6 showed no inhibition. Thus, for Gram negative bacteria also, maximum inhibition is observed by SOR-7 containing 2, 5-dichloro substitution. Whereas, SOR-4 and SOR-6 containing 2-methyl and 4-fluoro substitutions in aromatic ring had no effect on these bacteria. Thus, in DMSO, SOR-7 is the most effective compound for these bacteria and $P$. mirabilis is the most susceptible bacteria.

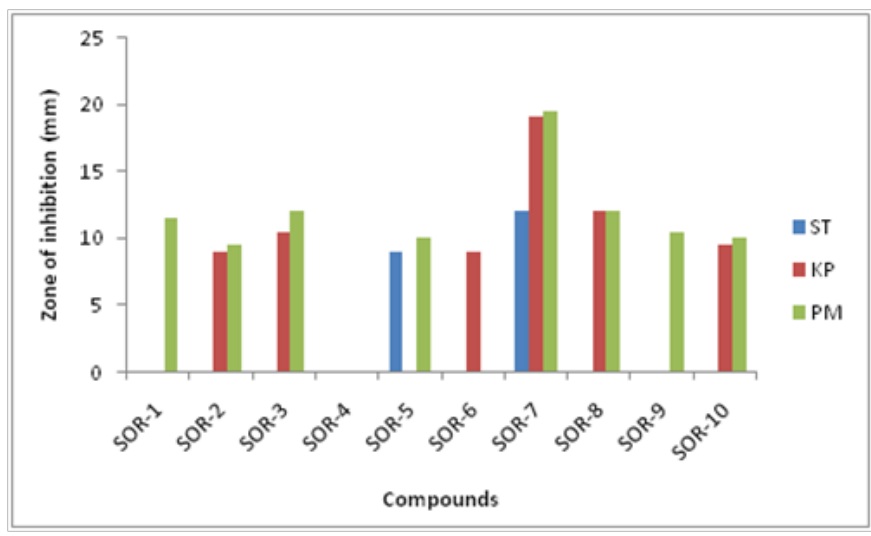

Figure 4 Zone of inhibition of SOR compounds against Gram negative bacteria in DMSO.

Figure 5 shows the zone of inhibition against Gram negative bacteria in DMF. Against all the three bacteria, again SOR-7 exhibited maximum inhibition. For S. typhimurium, inhibition is quite less in comparison to other two Gram negative bacteria; $K$. pneumonia and $P$. mirabilis. For this strain, inhibition is more or less same for all the compounds except SOR-9 which had no effect on this bacterium. The comparison of inhibition of SOR-9 (containing 3, 4-dichloro substitution) with that of SOR-7 (containing 2,5-dichloro substitution) suggests that position of substitution also plays an important role in inhibition. For K. pneumonia, all the compounds show inhibition and maximum inhibition is observed for SOR-7 containing 2, 5-dichloro substitution. Against $P$. mirabilis, SOR-10 exhibited minimum inhibition. SOR-1, SOR-2, SOR-4, SOR-5 and SOR-6 showed no inhibition at all. Thus, in DMF K. pneumonia is the most susceptible bacteria and compound with chloro substitution at 2 nd and 5 th position is most effective. So, overall, in SOR series, DMF is good solvent and nature and position of substituent play important role in inhibition.

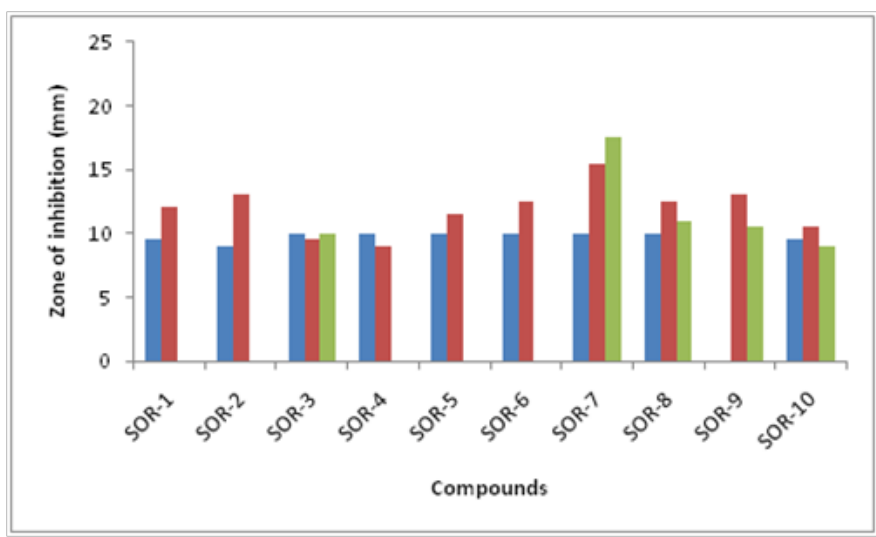

Figure 5 Zone of inhibition of SOR compounds against Gram negative bacteria in DMF.

Dihydropyrimidinethiones: Figure 6 shows the zone of inhibition against the Gram positive bacteria in DMSO for these synthesized compounds. It is observed that against S. aureus, SSR-1, SSR-2 and SSR-7 are not effective whereas SSR-6 exhibited maximum inhibition. For $B$. cereus, all the compounds showed inhibition and maximum is observed by SSR-5. Against B. megaterium, only SSR-4 had no inhibition and SSR-5 and SSR-6 exhibited maximum inhibition. So, overall, SSR-6 containing 4-fluoro group as substitution is effective in DMSO for these three Gram positive bacteria and B. cereus is the most susceptible bacteria. 


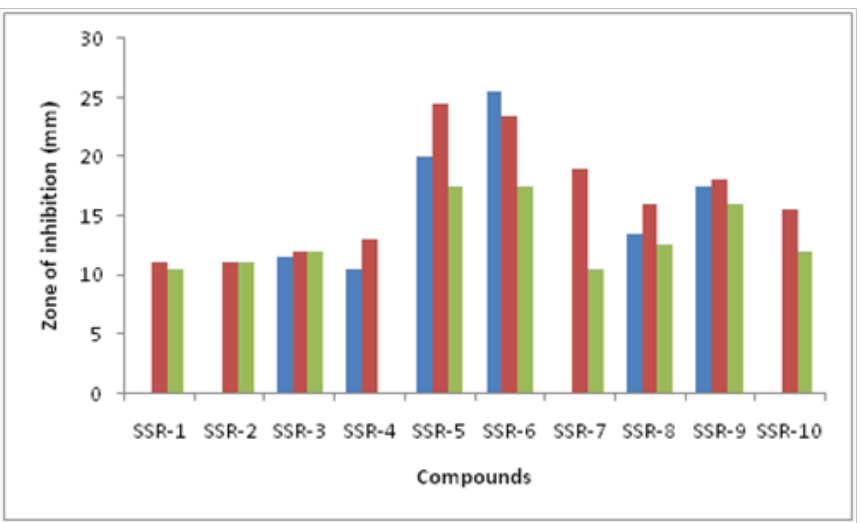

Figure 6 Zone of inhibition of SSR compounds against Gram positive bacteria in DMSO.

Figure 7 shows the zone of inhibition against the Gram positive bacteria in DMF where all the compounds exhibited inhibition against studied bacterial strains. However, again SSR-6 containing 4-fluoro substitution showed maximum inhibition for all the three bacterial strains.

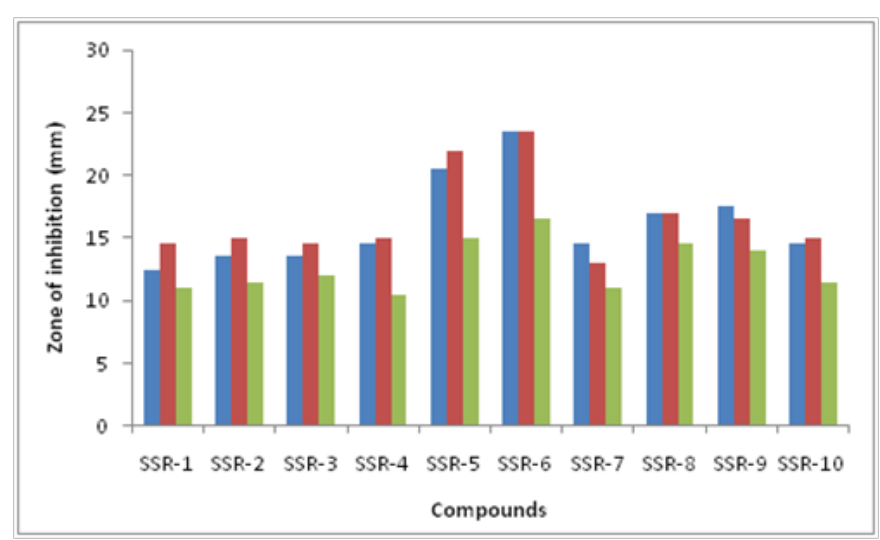

Figure 7 Zone of inhibition of SSR compounds against Gram positive bacteria in DMF.

\section{Comparison of inhibition in DMSO and DMF shows that inhibition is greater in DMSO than in DMF}

Figure 8 shows the zone of inhibition against Gram negative bacteria in DMSO. It is observed that for S. typhimurium, only SSR-5 showed inhibition and other compounds had no inhibition at all. Thus, 3-methoxy is effective in DMSO. Against $K$. pneumonia, SSR-10 had no effect whereas and SSR-6 exhibited maximum inhibition. Against P. mirabilis, all the compounds exhibited inhibition and SSR-5 and SSR-6 showed maximum inhibition. Thus, the presence of 3-methoxy (as in SSR-5) and 4-fluoro (as in SSR-6) are equally effective. Overall, 3-methoxy and 4-fluoro substitutions are most effective and S. typhimurium is the most resistant bacteria.

Figure 9 shows the zone of inhibition against Gram negative bacteria in DMF. In DMF, against all the three bacteria, SSR-5 exhibited maximum inhibition. For S. typhimurium, SSR-8 showed no inhibition. So, 3-chloro substitution is not effective. For $K$. pneumonia, SSR-1 and SSR-2 showed no inhibition whereas against P. mirabilis, inhibition is not shown by SSR-1 and SSR-4.

Thus, in DMF, overall, S. typhimurium is most susceptible bacteria and SOR-6 exhibited maximum inhibition in both the solvents. Thus, for these compounds, solvent and substitutions both play an important role in inhibition. The 4-fluoro substitution in SSR-6 is most effective in both DMSO and DMF against Gram positive bacteria. Against Gram negative bacteria also, DMF is found to be good solvent.

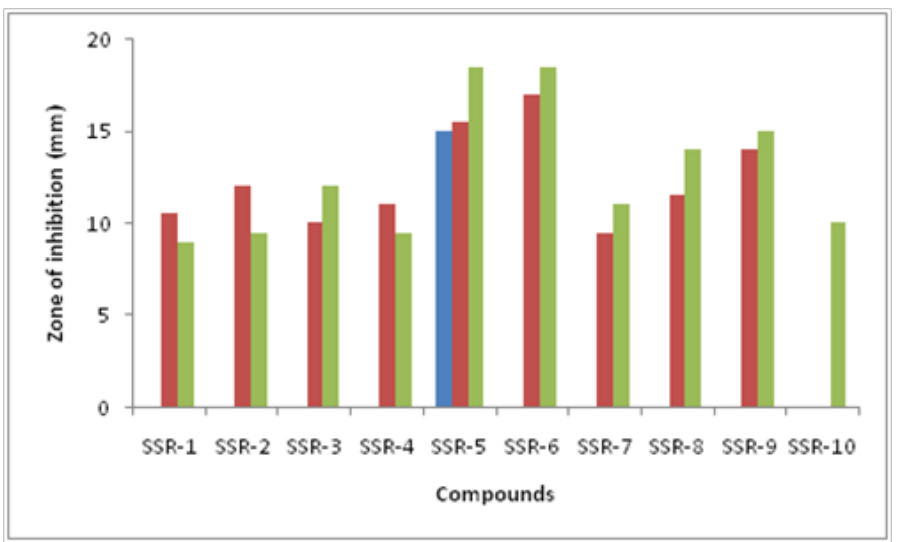

Figure 8 Zone of inhibition of SSR compounds against Gram negitive bacteria in DMSO.

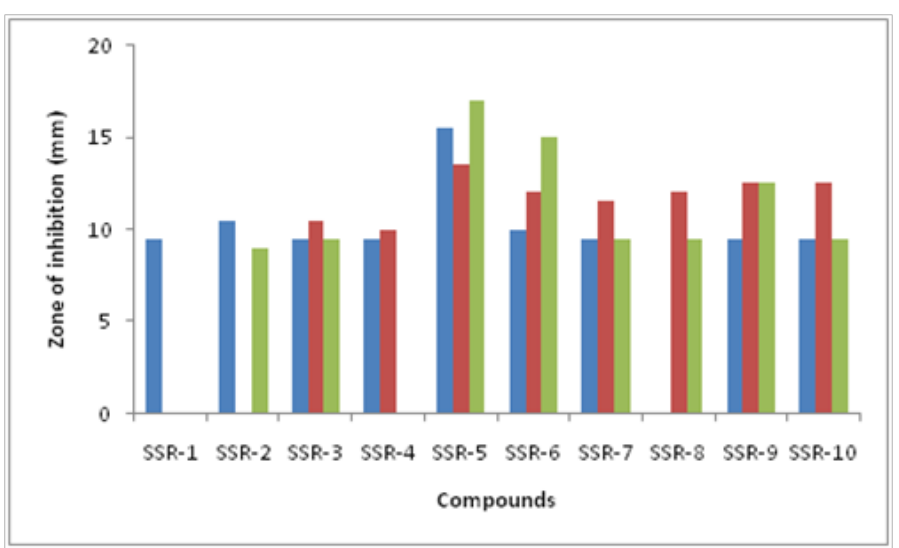

Figure 9 Zone of inhibition of SSR compounds against Gram negitive bacteria in DMF.

\section{Conclusion}

Comparison of structures of compounds of SOR and SSR series shows that there is slight change in moiety but substitutions are same. When the inhibition of these compounds is compared then a substitution which causes increase in inhibition in one series was not much effective in other series. This suggests that moiety also play an important role in inhibition.

\section{Acknowledgements}

None.

\section{Conflict of interest}

The author declares no conflict of interest.

\section{References}

1. Shimizu T, Yamada Y, Yasui H, et al. Clinical application of immune reactivity of dihydropyrimidine dehydrogenase (DPD) in gastric scirrhous carcinoma treated with S-1, a new DPD inhibitory fluoropyrimidine. Anticancer Res. 2005;25(4):2997-3001.

2. Adhikari A, Kalluraya B, Sujith KV, et al. Synthesis, characterization and biological evaluation of dihydropyrimidine derivatives. Saudi Pharma J. 2012;20(1):75-79. 
3. Phucho T, Nongpiur A, Tumtin S, et al. Recent progress in the chemistry of dihydropyrimidinones. Rasayan J Chem. 2009;2(3):662-676.

4. Gama FHS, de Souza ROMA, Garden SJ. An efficient green protocol for the preparation of acetoacetamides and application of the methodology to a one-pot synthesis of Biginelli dihydropyrimidines. Expansion of dihydropyrimidine topological chemical space. RSC Adv. 2015;5:7091570928.

5. Udayakumar V, Gowsika J, Panduranga A. A novel synthesis and preliminary in vitro cytotoxic evaluation of dihydropyrimidine2,4(1H,3H)-dione derivatives. J Chem Sci. 2017;129(2):249-258.

6. Wang X, Lou Q, Guo Y, et al. The design and synthesis of 9phenylcyclohepta[d]pyrimidine-2,4-dione derivatives as potent nonnucleoside inhibitorsof HIV reverse transcriptase. Org Biomol Chem. 2006;4:3252-3258.

7. Lukasik PM, Elabar S, Lam F, et al. Synthesis and biological evaluation of imidazo[4,5-b]pyridine and 4-heteroarylpyrimidine derivatives as anti-cancer agents. Eur J Med Chem. 2012;57:311-322.

8. Zarnegar Z, Safari J. Magnetic nanoparticles supported imidazoliumbased ionic liquids as nanocatalyst in microwave-mediated solvent-free Biginelli reaction. J Nanoparticle Res. 2014;16(8):2509.
9. Rawoof AN, Muzzaffar AM, Samiullah B, et al. Biological Activities and Synthetic Approaches of Dihydropyrimidinones and Thiones - An Updated Review. Curr Bioactive Compds. 2016;12(4):236-250.

10. Determann R, Dreher J, Baumann K, et al. 2-Anilino-4-(benzimidazol-2yl)pyrimidines - A multikinase inhibitor scaffold with antiproliferative activity toward cancer cell lines. Eur J Med Chem. 2012;53:254-263.

11. Zhong-Xing J, Sanjun Z, Wei Z. Recent progress on fluorous synthesis of biologically interesting compounds. Mol Diversity. 2014;18(1):203-218.

12. Maharramov AM, Ramazanov MA, Guliyeva GA, et al. Synthesis, investigation of the new derivatives of dihydropyrimidines and determination of their biological activity. J Mol Struc. 2017;1141:39-43.

13. Kiue A, Sano T, Naito A, et al. Reversal by two dihydropyrimidine compounds of resistance to multiple anticancer agents in mouse P388 leukemia in vivo and in vitro. Jpn J Cancer Res. 1990;81(10):1057-1064.

14. Riddick JA, Bunger WB, Sakano T. Organic Solvents-Physical Properties and Methods of Purification. Techniques of Chemistry, New York, USA; 1986. 